\title{
Relationship between Trading Volume and Asymmetric Volatility in the Korean Stock Market
}

\author{
Ki-Hong Choi ${ }^{1}$, Zhu-Hua Jiang ${ }^{2}$, Sang Hoon Kang ${ }^{3}$, Seong-Min Yoon ${ }^{{ }^{*}}$ \\ ${ }^{1}$ Department of Economics, Pusan National University, Busan, Korea \\ ${ }^{2}$ Research Institute of Social Criticality, Pusan National University, Busan, Korea \\ ${ }^{3}$ Department of Business Administration, Pusan National University, Busan, Korea \\ Email: *smyoon@pusan.ac.kr
}

Received May 27, 2012; revised June 25, 2012; accepted July 5, 2012

\begin{abstract}
We investigated the relationship between return volatility and trading volume as a proxy for the arrival of information to the market, based on Korean stock market (KSM) data from January 2000 to December 2010. We measured the relationship between return volatility and trading volume using the GJR-GARCH and exponential GARCH (EGARCH) models. We found a positive relationship between trading volume and volatility, suggesting that trading volume influences the flow of information to the market. This finding supports the validity of the mixture of distributions hypothesis. Considering that trading volume can also explain volatility asymmetry, we conclude that trading volume is a useful tool for predicting the volatility dynamics of the KSM.
\end{abstract}

Keywords: Asymmetry; Volatility; Trading Volume; Mixture of Distribution Hypothesis

\section{Introduction}

Volatility exhibits three typical patterns in most financial time series, namely, clustering, asymmetry, and persistence. In particular, many empirical studies have identified asymmetric volatility, by which stock return volatility tends to rise more following a large fall in price (bad news) than following a rise in price (good news) (Nelson [1]; Engle and $\mathrm{Ng}[2]$ ). We investigated the effects of trading volume on asymmetric volatility in the Korean stock market (KSM), by studying the relationship between volatility and trading volume as a proxy for the arrival of information (hereafter, information arrival) to the market.

We examined the relationship between stock returns and trading volume using the mixture of distributions hypothesis (MDH), in the context of information arrival. The MDH provides an explanation for volatility and volume by linking changes in price, volume, and the rate of information flow. The MDH implies a positive relationship between trading volume and volatility, as price changes simultaneously. Shifts to new equilibrium are immediate, and no intermediate processes form.

Many empirical studies supporting the MDH have explained volatility persistence by including trading volume as a proxy for information arrival using the general autoregressive conditional heteroskedasticity $(\mathrm{GARCH})$ model. But almost none of these studies considered asymmetric

${ }^{*}$ Corresponding author.
GARCH models. This study used the daily stock index and its trading volume on the KSM to explore the relationship between asymmetric volatility and trading volume, using two asymmetric GARCH models; exponential GARCH (EGARCH) and Glosten-Jagannathan-RunkleGARCH (GJR-GARCH) models.

The remainder of this paper is organized as follows. A literature review is presented in Section 2. Section 3 presents the data and descriptive statistics. Section 4 presents the methodology of the study. The empirical results are discussed in Section 5. Section 6 concludes the paper.

\section{Literature Review}

Economists have long been interested in studying the relationship between stock return volatility and trading volume. Studies on this relationship are usually theoretically based on either the sequential information arrival hypothesis (SIAH) or the MDH.

The seminal study of Copeland [3] assumed that traders receive new information in sequential random style; accordingly, he developed the SIAH. The traders change their trading positions as new information arrives to the market. However, not all traders receive this new information at exactly the same time. Hence, the response of each individual trader to this information represents an incomplete equilibrium. The final market equilibrium is established when all traders have received the information and have made a trading decision based on that information. Thus, 
the SIAH suggests that a lead-lag relationship between volume and volatility exists only in the presence of information.

However, the MDH offers a different explanation by linking changes in price, volume, and rate of information flow (Clark [4]; Epps and Epps [5]; Harris [6]). The MDH implies a positive relationship between trading volume and price variability, and this relationship is a function of a mixing variable defined as the rate of information flow. In the $\mathrm{MDH}$, the shift to a new equilibrium is immediate, and the partial equilibrium of the sequential information model never occurs. Clark [4] introduced this concept, which explores the role of trading volume as a proxy for a stochastic process of information arrival, for theoretically analyzing trading volume and the movement of stock prices.

Lamoureux and Lastrapes [7], testing the relationship between volume and volatility for a number of actively traded stocks in the United States, used contemporaneous trading volume as an explanatory variable in the variance equation and found that the inclusion of volume eliminated the persistence of volatility. Gallo and Pacini [8], using data on 10 actively traded US stocks from 1985 to 1995 , found that persistence decreased when trading volume was used in the conditional variance equation. Foster [9] tested the predictions of MDH for the oil futures market from 1990 to 1994 and found that volume and volatility were largely contemporaneously related and that both were driven by the same factor, which is assumed to be information arrival. Alsubaie and Najand [10] tested the effect of trading volume on the persistence of the conditional volatility of returns in the Saudi stock market. Overall, their results supported the MDH at the firm level.

However, not all studies support the MDH. For example, Sharma, Mbodja and Kamath [11] investigated the relationship between trading volume and volatility for the New York Stock Exchange (NYSE) index from 1986 to 1989. They found that trading volume did not completely explain the GARCH effect, and concluded that while trading volume might be a good proxy for information arrival about individual firms, it is not true for the market as a whole. Lee [12] investigated the relationship between trading volume and volatility of Korean markets using the threshold GARCH (TGARCH) model and found that there was asymmetric volatility in the Korea Composite Stock Price Index (KOSPI) and the Korean Securities Dealers Automated Quotations (KOSDAQ) market, but concluded that inclusion of trading volume did not reduce volatility persistence in the conditional variance equation.

An, Jang and Lee [13] examined the contemporaneous correlation as well as the lead-lag relationship between trading volume and return volatility on the Korean stock market and found evidence of a significant lead-lag relationship between trading volume and the return volatility using the SIAH. Kim and Kim [14] investigated the relationship between return volatility and volume of the KOSPI 200 futures index using the GJR-GARCH model. They identified volatility persistence, asymmetric responses to information arrival, and a relationship between return volatility and volume.

\section{Data and Descriptive Statistics}

Our primary data set consisted of a daily stock index and its trading volume on the Korea Exchange (KRX) from 4 January 2000 to 30 December 2010. Daily index returns and trading volume were calculated in terms of percentage logarithmic change, based on the following formulae:

$$
\begin{aligned}
& r_{t}=\ln \left(P_{t} / P_{t-1}\right) \times 100 \\
& V_{t}=\ln \left(T_{t} / T_{t-1}\right) \times 100
\end{aligned}
$$

where $P_{t}$ is the daily close of the index and $T_{t}$ is the trading volume.

Figure 1 shows the change in value of the KOSPI and its trading volume. Prices gradually increased until 2008, then dropped due to the 2008 global financial crisis, and then recovered. High trading volume was observed in 2002-2003 and then remained constant.

Table 1 lists the descriptive statistic for KOSPI returns and its trading volume. Mean return and trading volume were positive for the market. The kurtosis was positive for daily stock returns and trading volume, and greater than 3. Returns skewness was negative and trading volume skewness was positive. Applying the Jarque-Bera (J-B) test for normality rejected the null hypothesis of normality for returns and trading volume. The Q-statistic can be used to test whether a group of autocorrelations is significantly different from zero. The autocorrelation coefficient shows that returns did not exhibit a serial correlation whereas trading volume did.

Additionally, we tested the stationarity of returns and trading volume, for which the most common test is the

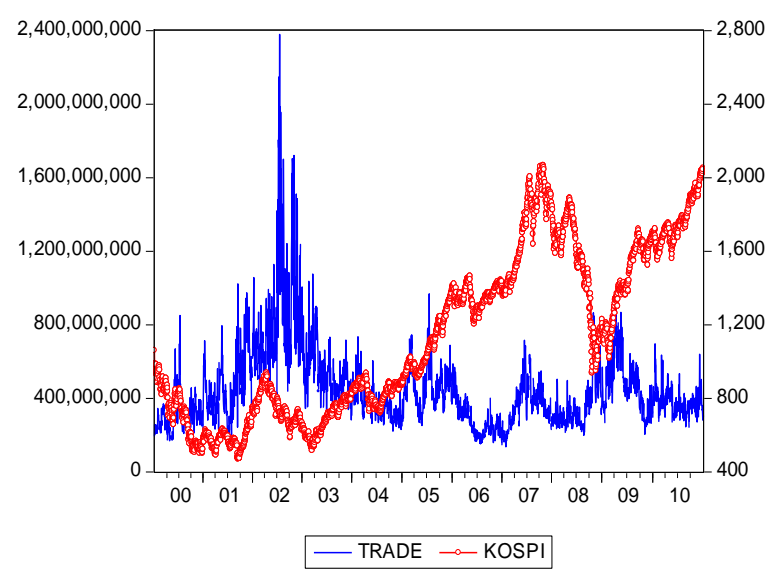

Figure 1. KOSPI index and trading volume. 
unit test. To test for a unit root, we employed both the augmented Dickey-Fuller (ADF) test and the PhillipsPerron (PP) test. Table 2 provides the results. The null hypothesis that returns and trading volume are nonstationary was rejected at the $1 \%$ significance level, indicating that both trading volume and returns are stationary.

\section{Methodology}

In general, the ARCH model of Engle [15] and the GARCH model of Bollerslev [16] are the most popular tools for capturing the volatility dynamics of financial time series. The GARCH model is particularly useful because it makes current conditional variance dependent on lags in its previous conditional variance. One of its primary limitations is that it enforces a symmetric response of volatility to both positive and negative market shocks, because conditional variance is regarded as a function of the magnitude of lagged residuals, not whether they are positive or negative. However, it has been argued that a negative market shock may lead to more volatility than a positive shock of the same magnitude. To account for this, Nelson [1] developed the EGARCH model and Glosten, Jagannathan and Runkle [17] introduced the GJR-GARCH model. This study used both of these models to assess asymmetric volatility and the effect of new information arrival to the market.

Table 1. Summary of descriptive statistics.

\begin{tabular}{ccc}
\hline & Returns & Trading Volume \\
\cline { 2 - 3 } Mean & 0.0234 & 0.0163 \\
Median & 0.1266 & -1.2264 \\
Maximum & 11.2843 & 143.8069 \\
Minimum & -12.8047 & -92.5004 \\
Std. Dev. & 1.8028 & 18.777 \\
Skewness & -0.5513 & 0.4688 \\
Kurtosis & 7.8372 & 6.0971 \\
J-B & $2789^{* * *}$ & $1186^{* * *}$ \\
Q(12) & 16.526 & $338.36^{* * *}$ \\
& $(0.168)$ & $(0.000)$ \\
\hline
\end{tabular}

Note: Jarque-Bera (J-B) is the test statistic for the null hypothesis of nomality in sample returns distributions. Ljung-Box Q(12) statistics test serial correlations up to a 12 th lag length. Significance levels: ${ }^{* * *} 1 \%,{ }^{* *} 5 \%,{ }^{*} 10 \%$.

Table 2. Unit root tests for returns and trading volume.

\begin{tabular}{cccc}
\hline & & Returns & $\begin{array}{c}\text { Trading } \\
\text { Volume }\end{array}$ \\
\cline { 3 - 4 } ADF Test & Intercept & $-51.06^{* * *}$ & $-25.12^{* * *}$ \\
& Trend and Intercept & $-51.08^{* * *}$ & $-25.12^{* * *}$ \\
PP Test & Intercept & $-51.12^{* * *}$ & $-180.98^{* * *}$ \\
& Trend and Intercept & $-51.15^{* * *}$ & $-183.08^{* * *}$ \\
\hline
\end{tabular}

Note: The critical value for the ADF and PP tests are -3.9611 and -3.4323 at the $1 \%$ significance level, respectively. Significance levels: ${ }^{* * *} 1 \%,{ }^{* *} 5 \%$, *10\%; ADF, augmented Dickey-Fuller test; PP, Phillips-Perron test.
The GJR-GARCH $(1,1)$ and EGARCH $(1,1)$ models with trading volume are defined as follows, respectively:

$$
\begin{gathered}
r_{t}=\mu+\varepsilon_{t} \\
\varepsilon_{t}=\sqrt{h_{t}} z_{t} \\
z_{t} \sim \text { i.i.d. with } E\left(z_{t}\right)=0, \operatorname{var}\left(z_{t}\right)=1 \\
h_{t}=\omega+\alpha \varepsilon_{t-1}^{2}+\beta h_{t-1}+\delta d_{t-1} \varepsilon_{t-1}^{2}+\theta V_{t} \\
\log h_{t}=\omega+\alpha\left[\frac{\left|\varepsilon_{t-1}\right|}{h_{t-1}}-\sqrt{2 / \pi}\right]+\beta \log h_{t-1}+\delta \frac{\varepsilon_{t-1}}{h_{t-1}}+\theta V_{t}
\end{gathered}
$$

where $r_{t}$ is the realized return of KOSPI, $\mu$ denotes the mean of the returns, and $V_{t}$ is trading volume, which is used as a proxy for information arrival to the market. Equation (6) specifies conditional variance as a function of mean volatility $\omega$, where $\varepsilon_{t-1}^{2}$ is the lag in the squared residual of the mean (the ARCH term) and provides information about volatility clustering, $h_{t-1}$ is the previously forecasted variance (the GARCH term), $d_{t-1} \varepsilon_{t-1}^{2}$ is a term that captures asymmetry, and $d_{t-1}$ is a dummy variable that is equal to one if $\varepsilon_{t-1}<0$ (bad news) and is equal to zero if $\varepsilon_{t-1} \geq 0$ (good news). When $\varepsilon_{t-1}<0$ and $d_{t-1}=1$, the effect of an $\varepsilon_{t-1}$ shock on $h_{t}$ is $(\alpha+\delta) \varepsilon_{t-1}^{2}$. If $\delta>0$, negative shocks will have a larger effect on volatility than positive shocks. In Equation (7), conditional variance is log-linear, which has several advantages over the pure GARCH specification. First, regardless of the magnitude of $\log h_{t}$, the implied value of $h_{t}$ can never be negative, but the coefficients can be negative. Second, instead of using $\varepsilon_{t-1}^{2}$, EGARCH model uses a standardized value of $\varepsilon_{t-1} / h_{t-1}$, which allows asymmetry to be considered. Hence, the effect of shock on log conditional variance is $(\alpha+\delta)$ if $\varepsilon_{t-1} / h_{t-1}$ is positive and $(-\alpha+\delta)$ if $\varepsilon_{t-1} / h_{t-1}$ is negative.

When trading volume is included in the variance equation, $\theta=0$ in both GJR-GARCH $(1,1)$ and EGARCH $(1,1)$ models when the effect of trading volume on conditional variance is ignored. In the two asymmetric models, the persistence of conditional variance is measured by $(\alpha+\beta)$, where a larger value indicates greater persistence of market shock. If trading volume is considered a proxy for information arrival, then it is expected that $\theta>0$. If $(\alpha+\beta)$ is smaller when trading volume is included than when it is excluded, then $\alpha$ or $\beta$ may be insignificant.

We also tested the relationship between return volatility and lagged trading volume as follows:

$$
\begin{gathered}
h_{t}=\omega+\alpha \varepsilon_{t-1}^{2}+\beta h_{t-1}+\delta d_{t-1} \varepsilon_{t-1}^{2}+\theta V_{t-1} \\
\log h_{t}=\omega+\alpha\left[\frac{\left|\varepsilon_{t-1}\right|}{h_{t-1}}-\sqrt{2 / \pi}\right]+\beta \log h_{t-1}+\delta \frac{\varepsilon_{t-1}}{h_{t-1}}+\theta V_{t-1}
\end{gathered}
$$

where $V_{t-1}$ is lagged trading volume. All parameters of variance in Equations (6)-(9) can be estimated using the 
Brendt, Hall, Hall, and Hausman (BHHH) algorithm, assuming Student's t-distribution innovation.

The distribution of the actual returns is shown as the histogram in Figure 2. The histogram of returns has a more pronounced peak than a normal distribution, that is, it is more similar to a t-distribution and, thus, the t-distribution may be more appropriate to the error term assumption. Assuming the innovations follow Student's t-distribution, the log-likelihood function is defined as follows:

$$
\begin{aligned}
\log L= & T\left\{\log \Gamma\left(\frac{v+1}{2}\right)-\log \Gamma\left(\frac{v}{2}\right)-\frac{1}{2} \log [\pi(v-2)]\right\} \\
& -\frac{1}{2} \sum_{t=1}^{T}\left[\log h_{t}+(1+v)\left[\log \left(1+\frac{\varepsilon_{t}^{2}}{h_{t}(v-2)}\right)\right]\right]
\end{aligned}
$$

where the degree of freedom $v>2$ controls the tail behavior. The t-distribution approaches normal distribution as $v \rightarrow \infty$.

\section{Empirical Results}

Table 3 shows the estimation results of GJR-GARCH and EGARCH model excluding trading volume variable. The coefficients $\alpha$ and $\beta$ represent $\mathrm{ARCH}$ and GARCH terms, respectively, and are shown to be statistically significant at the $1 \%$ level. The dynamics of returns exhibit high persistence in conditional variance. Note that the asymmetry term, $\delta$, has the correct sign and is significant at the $1 \%$ level. These results imply that good news has a smaller effect on conditional volatility than bad news, that is, the market exhibits asymmetry.

Table 4 presents the results when contemporaneous trading volume is included. The GARCH term $(\beta)$ is statistically significant at the $1 \%$ level in both models, whereas the $\mathrm{ARCH}$ term $(\alpha)$ is significant in EGARCH

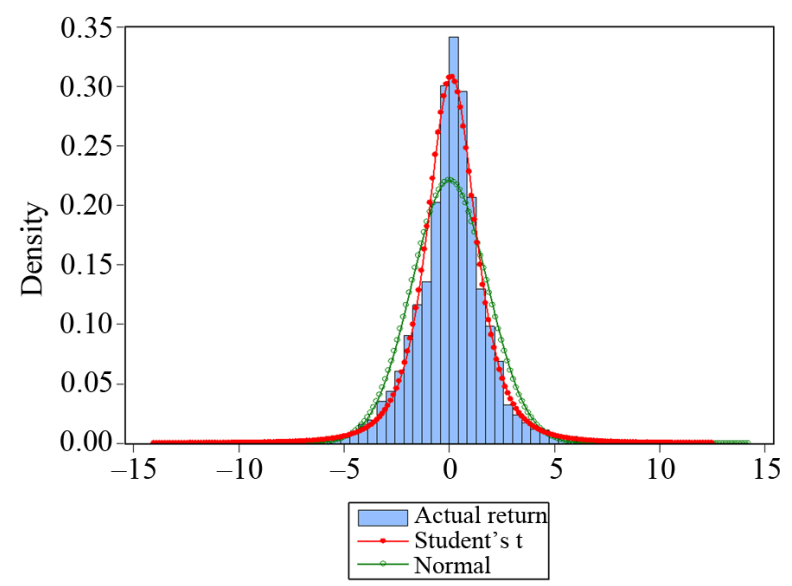

Note: Comparison of actual returns distribution to a standardized normal and Student's t-distribution. The t-distribution assumes a greater likelihood of large returns than does the normal distribution.

Figure 2. Returns of the KOSPI. but not in GJR-GARCH models. The coefficient of trading volume $(\theta)$ is positive and statistically significant at the $1 \%$ level in both models. These results suggest that contemporaneous volume significantly explains volatility, supporting the MDH. Including trading volume slightly increases $\delta$, implying that volume leads to more asymmetric volatility on the market.

Table 5 shows the estimation results of the two models when lagged trading volume is included in the conditional variance equation. The estimated coefficients of $\alpha$, $\beta$, and $\delta$ are highly significant but the lagged trading volume coefficients are not significant. So we conclude that lagged trading volume does not significantly reduce persistence and does not explain volatility and, thus, does not support the SIAH.

We evaluated the accuracy of each model specification using Ljung-Box $Q_{s}(12)$ and $\mathrm{ARCH}(5)$ tests, as shown in Tables 4 and 5. Neither test was significant at the 1\% level, indicating that both models are sufficient for meas-

Table 3. Estimation results of GJR-GARCH and EGARCH models without trading volume.

\begin{tabular}{ccc}
\hline & GJR-GARCH $(1,1)$ & EGARCH $(1,1)$ \\
\cline { 2 - 3 }$\omega$ & $0.036^{* * *}$ & $-0.107^{* * *}$ \\
& $(0.008)$ & $(0.014)$ \\
$\alpha$ & $0.021^{*}$ & $0.159^{* * *}$ \\
\multirow{2}{*}{$\beta$} & $(0.012)$ & $(0.020)$ \\
& $0.911^{* * *}$ & $0.979^{* * *}$ \\
$\delta$ & $(0.001)$ & $(0.004)$ \\
\multirow{2}{*}{$Q_{S}(12)$} & $0.103^{* * *}$ & $-0.089^{* * *}$ \\
& $(0.017)$ & $(0.013)$ \\
$\operatorname{ARCH}(5)$ & 9.878 & $14.176^{* *}$ \\
& {$[0.541]$} & {$[0.290]$} \\
& 1.041 & $1.501^{* *}$ \\
\hline
\end{tabular}

Note: Standard errors are in parentheses and p-values are in brackets. The Ljung-Box $Q_{s}(12)$ statistic tests serial correlations up to a 12th lag length in the squared standardized returns. The $\mathrm{ARCH}(5)$ statistic tests the $\mathrm{ARCH}$ effects at 5 th order lagged, squared residuals. Significance levels: ${ }^{* * *} 1 \%$, *** $5 \%,{ }^{*} 10 \%$.

Table 4. Estimation results of GJR-GARCH and EGARCH models with contemporaneous trading volume.

\begin{tabular}{ccc}
\hline \multirow{2}{*}{$\omega$} & GJR-GARCH $(1,1)$ & EGARCH $(1,1)$ \\
\cline { 2 - 3 }$\alpha$ & $0.037^{* * *}$ & $-0.099^{* * *}$ \\
& $(0.009)$ & $(0.014)$ \\
\multirow{2}{*}{$\beta$} & 0.0183 & $0.148^{* * *}$ \\
& $(0.007)$ & $(0.019)$ \\
$\delta$ & $0.909^{* * *}$ & $0.977^{* * *}$ \\
& $(0.011)$ & $(0.004)$ \\
$\theta$ & $0.111^{* * *}$ & $-0.103^{* * *}$ \\
& $(0.017)$ & $(0.013)$ \\
$Q_{s}(12)$ & $0.010^{* * *}$ & $0.007^{* * *}$ \\
& $(0.003)$ & $(0.002)$ \\
ARCH $(5)$ & 7.675 & 6.954 \\
& {$[0.810]$} & {$[0.861]$} \\
\hline
\end{tabular}

Note: See Table 3. 
Table 5. Estimation results of GJR-GARCH and EGARCH models with lagged trading volume.

\begin{tabular}{ccc}
\hline & GJR-GARCH $(1,1)$ & EGARCH $(1,1)$ \\
\cline { 2 - 3 }$\omega$ & $0.037^{* * *}$ & $-0.107^{* * *}$ \\
$\alpha$ & $(0.008)$ & $(0.014)$ \\
\multirow{2}{*}{$\beta$} & $0.023^{* * *}$ & $0.158^{* * *}$ \\
& $(0.011)$ & $(0.019)$ \\
$\delta$ & $0.912^{* * *}$ & $0.980^{* * *}$ \\
\multirow{2}{*}{$\theta$} & $(0.011)$ & $(0.004)$ \\
& $0.097^{* * *}$ & $-0.087^{* * *}$ \\
$Q_{s}(12)$ & $(0.017)$ & $(0.013)$ \\
& -0.005 & -0.001 \\
ARCH (5) & $(0.003)$ & $(0.002)$ \\
& 10.255 & $14.190^{* * *}$ \\
& $(0.594)$ & {$[0.289]$} \\
\hline
\end{tabular}

Note: See Table 3.

uring the effects of information arrival to the market, when trading volume is included.

\section{Conclusions}

We examined the persistence of return volatility on the Korean Stock Market (KSM), both including and excluding trading volume as a proxy for information flow, and considering lagged volume.

The main conclusions of this study are as follows. First, the KSM index exhibits strong volatility persistence and asymmetry. Second, the inclusion of contemporaneous trading volume in the GJR-GARCH and EGARCH models results in a positive relationship between trading volume and volatility. Third, when contemporaneous and lagged trading volumes are included in the conditional variance equation, the former is positively correlated with volatility but the latter is not. Thus, trading volume affects the flow of information, supporting the validity of $\mathrm{MDH}$. Finally, the asymmetric effect of bad news on volatility is higher when contemporaneous trading volume is included, although market shocks, whether positive or negative, have similar effects on conditional volatility. Thus, we conclude that trading volume is a useful tool for predicting the volatility dynamics of the KSM.

\section{Acknowledgements}

This work was supported by the National Research Foundation of Korea Grant, funded by the Korean Government (NRF-2011-330-B00044).

\section{REFERENCES}

[1] D. B. Nelson, "Conditional Heteroskedasticity in Asset Returns: A New Approach," Econometrica, Vol. 59, No. 2, 1991, pp. 323-370. doi:10.2307/2938260

[2] R. F. Engle and V. K. Ng, "Measuring and Testing the Impact of News on Volatility," Journal of Finance, Vol.
48, No. 5, 1993, pp. $1749-1778$. doi:10.1111/j.1540-6261.1993.tb05127.x

[3] T. E. Copeland, "A Model of Asset Trading under the Assumption of Sequential Information Arrival," Journal of Finance, Vol. 31, No. 4, 1976, pp. 1149-1168. doi: $10.2307 / 2326280$

[4] P. K. Clark, "A Subordinated Stochastic Process Model with Finite Variance for Speculative Prices," Econometrica, Vol. 41, No. 1, 1973, pp. 135-155. doi:10.2307/1913889

[5] T. W. Epps and M. L. Epps, "The stochastic Dependence of Security Price Changes and Transaction Volumes: Implications for the Mixture-of-Distributions Hypothesis," Econometrica, Vol. 44, No. 2, 1976, pp. 305-321. doi: $10.2307 / 1912726$

[6] L. Harris, "Cross-Security Tests of the Mixture of Distributions Hypothesis," Journal Financial and Quantitative Analysis, Vol. 21, No. 1, 1986, pp. 39-46. doi:10.2307/2330989

[7] C. G. Lamoureux and W. D. Lastrapes, "Heteroskedasticity in Stock Return Data: Volume versus GARCH Effects," Journal of Finance, Vol. 45, No. 1, 1990, pp. 221229. doi:10.1111/j.1540-6261.1990.tb05088.x

[8] G. M. Gallo and B. Pacini, "The Effects of Trading Activity on Market Volatility," European Journal of Finance, Vol. 6, No. 2, 2000, pp. 163-175. doi: $10.1080 / 13518470050020824$

[9] A. J. Foster, "Volume-Volatility Relationship for Crude Oil Futures Markets," Journal of Futures Markets, Vol. 15, No. 8, 1995, pp. 929-951. doi:10.1002/fut.3990150805

[10] A. Alsubaie and M. Najand, "Trading Volume, TimeVarying Conditional Volatility, and Asymmetric Volatility Spillover in the Saudi Stock Market," Journal of Multinational Financial Management, Vol. 19, No. 2, 2009, pp. 139-159. doi:10.1016/i.mulfin.2008.09.002

[11] J. L. Sharma, M. Mbodja and R. Kamath, "Heteroscedasticity in Stock Market Indicator Return Data: Volume versus GARCH Effects," Applied Financial Economics, Vol. 6, No. 4, 1996, pp. 337-342. doi:10.1080/096031096334132

[12] C. S. Lee, "A Study on the Trading Volume and Market Volatility," Journal of Industrial Economics and Business, Vol. 22, No. 2, 2009, pp. 495-511.

[13] S. C. An, S. W. Jang and S. H. Lee, "A Study on the Lead-Lag Relation between the Trading Volume and the Return Volatility in the KSE," Management \& Economy Research, Vol. 14, No. 1, 2006, pp. 19-33.

[14] S. A. Kim and Y. J. Kim, "An Examination of the Return Volatility-Volume Relationship using TGARCH Model in KOSPI200 Futures," Journal of Industrial Economics and Business, Vol. 21, No. 3, 2008, pp. 1161-1181.

[15] R. F. Engle, “Autoregressvie Conditional Heteroscedasticity with Estimates of the Variance of United Kingdom Inflation," Ecomometrica, Vol. 50, No. 4, 1982, pp. 987 1007. doi:10.2307/1912773

[16] T. Bollerslev, "Generalized Autoregressive Conditional Heteroskedasticity," Journal of Econometric, Vol. 31, No. 
3, 1986, pp. 307-327. doi:10.1016/0304-4076(86)90063-1

[17] L. R. Glosten, R. Jagannathan and D. E. Runkle, "On the Relation between the Expected Value and the Volatility of the Nominal Excess Return on Stocks," Journal of Finance, Vol. 48, No. 5, 1993, pp. 1779-1801. doi:10.1111/j.1540-6261.1993.tb05128.x 